\title{
Consumer choice in an energy efficient lighting context
}

\author{
Jabavu Clifford Nkomo \\ Energy and Development Research Centre, University of Cape Town
}

\begin{abstract}
Wide use of compact fluorescent lamps (CFLs) offers opportunity for residential savings with favourable environmental benefits. The size of the South African residential market shows that there are strong opportunities to be optimised. To exploit such opportunities, it is important to look at strategies that influence independent and interdependent consumer choice in lighting, and to examine how far these strategies have been successful in promoting the market penetration of CFLs. While this is so, there are some areas of concern about the performance of the product that have to be addressed, as well as need for public action arising from external diseconomies of consumption.
\end{abstract}

Keywords: residential lighting, compact fluorescent lamps, public awareness, market transformation

\section{Introduction}

Energy literature proclaims that compact fluorescent lamps (CFL) are an icon of energy efficiency, and that they have favourable economic and environmental benefits over their incandescent counterparts. Their benefits over incandescents are that they are easy to install, fit regular lighting fixtures, have a longer life expectancy and use less electricity to produce the same amount of light and cut costs by over 80 percent.

In this paper, it is argued that the huge potential residential market for CFL in South Africa can be optimised by adopting strategies, not only based on pure consumption, but which also take into account preference interdependence in society and habit formation in choice making. These strategies determine the degree of market penetration as well as the savings that accrue to the consumer. To the extent that gains to society are important, and we find it of public policy interest to address issues that do not promote consumer satisfaction and social welfare as a result of consumption of CFLs.

\section{The potential lighting market}

Table 1 , based on available information, indicates the potential size of the South African residential market. Population is shown by geographic provinces and the income spread using an LMS (Living Standard Measures) market segmentation model, and expresses the degree of income inequality, and the close linkage between poverty and inequality. These variables influence consumer economic and social outcomes. Apart from the household income levels and ownership of durables, other variables used to derive LSMs are access to urban infrastructure (making electricity very important), ownership of financial products and consumer shopping behaviour. So the higher the LSM, the greater the composite of wealth. Even without information on many dimensions of household well-being such as their consumption behaviour, savings, employment, health, education, housing, and other sources of income, the table gives valuable information that except for the Northern Cape Province, there are strong market opportunities to be optimised for CFLs. Much of the market potential comes from Government drive to increase access to electricity, the Reconstruction and Development Programme (RDP) households that are being electrified at an average rate of 250000 per year, and new mid-to-upper income households, which are approximately 5 million (ELI South Africa Document: 2000).

Apart from the diversity of consumers exhibited in Table 1, energy consumption patterns among households also vary depending on fuel prices, sources of income, and access to energy sources. Multiple fuel use is common.

All CFL lamps sold are imported, and are subject to high import tax and fluctuations in foreign exchange. Local manufacturing is relatively of low priority. The import duty on CFLs has not been an incentive to local manufacture.

\section{Strategies to influence consumer choice Consumer behaviour}

If we assume economic rational behaviour on the part of households, consumers make an optimal choice subject to the budget constraints they face. In this view, the purchase of a CFL is based on the consumer's subjective evaluation, and preferences for the product. The consumer makes a purchase if he perceives that the resulting utility gained by 
Table 1: Consumer market segmentation (in millions)

Source: ELI South Africa Strategy Document, Bonesa, November 2000

\begin{tabular}{lcccccc}
\hline & & LMS4 & LMS5 & LMS6 & LMS7 & LMS8 Total \\
\hline Eastern Cape & 0.787 & 0.715 & 0.579 & 0.572 & 0.501 & 7.150 \\
\hline Free State & 0.353 & 0.504 & 0.252 & 0.302 & 0.302 & 2.520 \\
\hline Gauteng & 0.796 & 1.680 & 1.326 & 2.210 & 2.210 & 8.840 \\
\hline Kwa-Zulu Natal & 1.010 & 1.010 & 1.010 & 1.179 & 0.926 & 8.420 \\
\hline Mpumalanga & 0.479 & 0.378 & 0.151 & 0.277 & 0.277 & 2.520 \\
\hline Northern Cape & 0.126 & 0.109 & 0.092 & 0.210 & 0.101 & 0.840 \\
\hline Limpopo Province & 0.798 & 0.294 & 0.168 & 0.168 & 0.084 & 4.200 \\
\hline North West & 0.403 & 0.302 & 0.269 & 0.370 & 0.235 & 3.360 \\
\hline Western Cape & 0.278 & 0.695 & 0.509 & 0.695 & 0.648 & 4.630 \\
\hline Total & 5.029 & 5.687 & 4.357 & 5.983 & 5.285 & 42.480 \\
\hline
\end{tabular}

Note: Lower income levels LSM 1 - LSM3 have been excluded from the above table, due to the fact that they are not yet targeted as part of the promotional programme.

investing in the CFL is worth paying the first high cost, and giving a high return on investment (a short payback period).

Another view is that rather than assuming economic rationality, preferences of consumers are affected by choices of other members of society, so that the different utility functions of different households are interdependent. In this view, consumers on their own are unable to evaluate hypothetical economic alternatives accurately. Decision-making is also influenced by factors such as existing knowledge and habit. If the consumer perceives the price to be too high without budgetary constraints, and without the understanding of economic benefits, this becomes a first high cost psychological barrier (Veich, 1994). Similarly, if the investment is costefficient but budget limits purchase, the first high cost becomes a barrier.

\section{Advertising and public awareness}

The above second view recognises the importance of advertising and public awareness in influencing consumer's investment choice in efficient lighting, although the extent of the influence varies from one consumer to another. As we know, the consumer's disposable income affects the level of the volume of sales from a given level of advertising expenditure. Advertising occurs in a world in which information is neither perfect nor free. Advertising not only informs the consumers about the existence and characteristics of CFLs, but also influences their economic behaviour not only by inducing them to switch from the incandescents, but also to shop around for lower prices of CFLs and at a lower cost.

While advertising may be seen as a way of increasing the market share of the product, it also tends to increase the price elasticity of demand for products, so that the greater the price elasticity, the more competitive the market, and frequently, the lower the price. The danger is when only one brand or type of CFL is advertised as this gives the advertiser more latitude to raise its price and profits, as in the case of a monopoly. Even in the case of consumer brand loyalty, the sellers can raise the price without losing their market to competitors. In most cases, however, advertised products tend to be priced higher than the less-known ones, and have an advantage in influencing the consumer into thinking that the advertised product is better than the rest. It is beneficial to society if advertising provides trustworthy information to consumers about the product quality.

Information on public awareness (public education and marketing) enlarges the set from which consumers make their choices. Information on lighting efficiency is scarce, and consumers need assistance to achieve their rational economic objectives and improve their net social welfare. There is a lack of reliable data on energy use as well as low awareness levels, and households do not know the proportion of their electricity bill going to various end uses to enable them to optimise on energy usage. Information on efficient technologies available is not pervasive, and while it exists, it is poorly disseminated or in an inaccessible form thereby being a constraint to the adoption of energy efficiency. Households need to know about the costs, savings and benefits generated by efficient lighting. Policy makers, on the other hand, need to understand consumer lighting behaviour and their acceptance of energy efficiency. This, in turn, enhances consumer understanding and market acceptance efficient lighting technologies. Without intervention, the most important role player, who should be prepared to implement energy efficient lighting, will not do so because of other priorities.

Once a choice is made, the consumer will look for positive affirmation information about the CFL. 
Comparison between performance of the lamp and prior expectation leads either to satisfaction or dissatisfaction with the CFL. Related to the concept of time preference, satisfaction increases the probability of carrying out a similar decision on choice at a future time period. As the market is transformed with increased levels of awareness, the market for CFL is expected to gain its own momentum.

Efforts in South Africa to raise public awareness include:

- Public education and marketing. Channels used include local, regional and national radio, television, print media, advertisements and informational brochures. As in Clark (1998), marketing programmes should include information campaigns on energy efficiency and efficiency lighting, advertise special terms for purchase (discounts, rebates, coupon schemes, leasing, etc), where lamps can be acquired, and so forth. Low-income households are generally averse to risk, and are likely to have a lower take-up of CFLs compared to the other groups because of the high initial purchase cost and lack of knowledge and understanding of benefits involved. Marketing particularly for the lowincome households reinforces media marketing by physical distribution of CFLs.

- Customer support service. Support must be easily accessible for the programme to retain its customers in efficient lighting technologies.

- Third party involvement. Eskom should ensure that it maintains effective and efficient programme management structures to maximise the opportunity for involvement of the following role players: the local service providers, lamp retailers, community based organisations supporting distribution lamps to low-income households, energy sector organisations, etc. This is likely to be more socially beneficial than television commercials that feature few facts.

\section{Market transformation}

Sales data of CFLs is sparse, and the distribution of various lamp types sold to different sectors of the economy is reported in aggregate terms. No breakdown of sales data is available for the residential market alone.

Figure 1 shows that the market share (of all lamps sold in South Africa) for incandescents has been falling overtime, its dominance of the market share falling from 80 percent in 1997 to 70 percent in 2002. The market share for the CFLs, on the other hand, rose from 2 percent to 7 percent between the same period of time (Figure 2). Although the number of our observations is limited, a least squares trend equation, requiring that the sum of squares of the difference between the actual values and calculated trend values be a minimum, reveals negative trend increment for the incandes- cent (-1.25), and a positive value for CFLs (0.64). These are amounts by which trend values increase or decrease.

The actual sales figures for incandescent bulbs exhibit an average growth rate of 0.6 percent between 1997 and 2002, with the sales rising from 50.6 million in 1997, reaching a peak of 65.4 million in 2000, and falling thereafter (50.3 million in 2002). Except for 1999 and 2000, the other years show a negative growth rate in sales. Sales of CFLs have an upward trend, with an average growth rate of 33.4 percent between 1997 and 2002, with sales rising from 1.45 million in 1997 to 5.35 million in 2002. This provides solid evidence that market transformation is taking place. A further market development has been the rapid decline in average retail prices for CFLs, which is favourably linked to affordability, access and penetration.

A simple extrapolation based on Figures 1 and 2 shows that a breakeven point in sales of both incandescent and CFL lamps is reached by 2006, at about 15 million sales per lamp type. This seems idealistic, as the incandescent players (firms or marketers) will not be passive and idly watch their market being eroded. Instead, assuming rationality, both players may uncompromisingly fight for a competitive edge over the other so as to regain their market share (incandescent) or consolidate their market gains (CFLs). The important point is on winning the consumer on product choice.

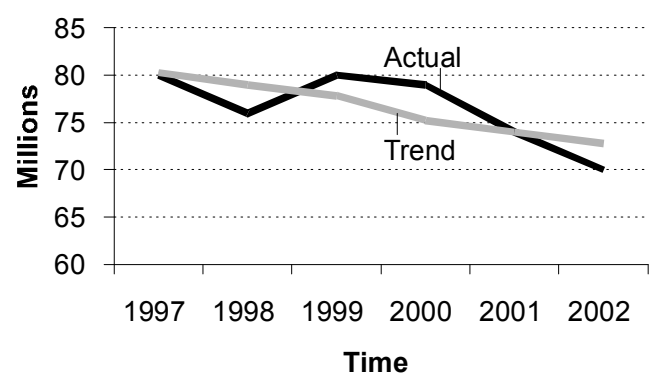

Figure 1: Sales of incandescent bulbs Source: Developed from data supplied by Bonesa

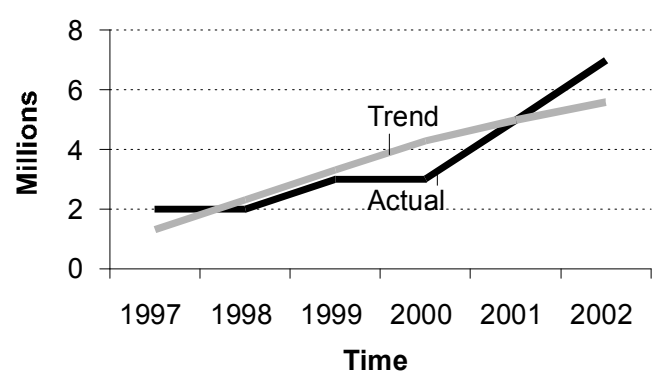

Figure 2: Lamp sales - market share for CFLs Source: Developed from data supplied by Bonesa

Higher penetration of CFLs in the market can, among other strategies, be achieved by appealing 
directly to consumers at all income levels. This would involve additional strategies like making the bulb 'visible' and more accessible at distribution points particularly chain stores. Most distribution networks that supply lighting and electrical products to retailers in high-density townships and rural areas do not carry CFLs. Aggressive promotion of CFLs in these and other outlets would increase the likelihood of CFL sales and penetration, and sustain their existence over time.

\section{Potential benefits}

The household may maximise its utility function, subject to constraints available, by moving from a lower investment to a higher investment lighting technology, a move that should increase its net social welfare. The resulting energy consumption savings from such substitution is a function of variables as the changes in wattage, the number of fittings and the operating hours of the lighting system. CFLs averages 10000 hours and consume only a quarter of electricity, while a typical standard incandescent may last between 750 to 1000 hours. This implies that every CFL purchased replaces 10 to 13 incandescent lamps, with improved energy saving and longevity making CFL one the best energy efficient investments available.

Consumers may burn the more efficient light for longer periods knowing that they will still save on the electricity bill. Taking the case of a CFL substituting an incandescent bulb, the actual savings can be expressed as snapback (or rebound) factor times gross savings to avoid estimating net savings, where:

Actual savings $=($ Inc wattage $*$ Inc Operating Hours) - (CFL wattage * CFL Operating Hours) (1)

Gross savings $=($ Inc wattage - CFL wattage $) *$ CFL Operating Hours

Snapback $=$ (Actual savings/gross savings)

Inc $=$ Incandescent

The total savings per household can be calculated by multiplying the actual (net) savings by the number of bulbs replaced and by the price per wattage (Equation 1).

At an aggregate level, a substantial substitution of CFLs for incandescents would yield enormous benefits. By reducing household lighting costs without reducing the lighting levels, it improves its cash flow and releases money for other household needs. Installation can reduce lighting expenditure by more than 70 percent, while producing the same or better quality of light. This reinforces demand for energy efficient lighting. Second, because lighting coincides with peak electricity demand, the reduction in energy use serves to alleviate the growing peak load. Furthermore, the reduction in peak load offers Eskom an opportunity to defer investment in generation, transmission and distribution capacity, but suffers reduced revenues from reduced electricity bills associated with energy efficiency. Eskom is yet to adopt a policy in which cost recovery is acceptable in the short-term, while securing revenue recovery in the longer-term (Clarke, 2001). Finally, substitution yields benefits to the local and global environment by reducing pollutants from coal-fired power stations. Positive spin-offs are in reducing emissions of greenhouse gas (GHG) in reducing global greenhouse gas pollutants, especially $\mathrm{CO}_{2}$ into the atmosphere. The GHGs are known for their changes in the world's climate, with the danger that their emissions may cause global devastation in the foreseeable future.

\section{Areas of concern with CFLs}

There are still areas of concern or problems with CFLs in the South African residential lighting market. As in Koford (1996), some lamps are slow to start, and take at least 45 to 60 seconds before full light output is reached. This problem may be related to low-quality lamps that emit poor light, and in turn affecting the image of high quality lamps. Some recommend that lower lighting levels can be compensated by using a lamp level that is 10 percent higher than the recommended (Kofod, 1996) or using a three-to-one wattage equivalence between a CFL and incandescent instead of the recommended five-to-one ratio (Palmer and Boardman, 1998).

Some studies also show that flickers from fluorescent lamps affect people's hypersensitive to electricity (Beckstead and Boyce 1992, Lundberg 1996, Palmer and Boardman 1998), but these studies also acknowledge that this is not a problem with high frequency electronic ballasts. Common with other international observations (www. Lightside.net, 2003), the colour from some lamps is cool, too white and unnatural. According to Palmer and Boardman (1998), ignorance and uncertainty account for non-ownership than dislike for the lamp. The main problem is persistent information failure on energy efficiency that would help consumers on their choice for lamps.

\section{A case for consumer protection}

Several insights emerge on the use of CFLs giving room for public action. While public information is necessary to verify the quality of CFLs in the market, there is also a need to regulate their safe disposal. This justifies the state to use its position to insist on the provision of information and to narrow the knowledge gap.

Available evidence indicates that global produc- 
tion capacity is far greater than demand. This explains the continued decrease in prices of CFLs globally. With the product price decrease, quality becomes a crucial issue. Downward price pressures leads to a proliferation of less quality products, with consumers finding it increasingly difficult to distinguish between low-quality and high-quality lamps. A consumer should be able to distinguish between high- and low-quality products. Sales of poor-quality lamps damage consumer trust in CFLs about their life to justify their cost, damage the market for the product given high expectations resulting from advertisements and information, and thus undermine the potential for energy saving benefits. This makes the role of independent testing, labelling and standards increasingly important. For this reason, Bonesa, whose primary objective was to implement the Energy Lighting Initiative in South Africa, was promoting the 'green leaf' logo as a symbol of a high quality lighting product. The purpose of the logo is to assist consumers to identify the CFL to use. The logo carries a message of both excellence and environmental friendliness, indicates that the lighting conforms to minimum standards of efficiency, and assures consumers that the lamps will last long enough to justify their high costs. Marketing strategists argue that branding is an integral part of a brand's evolution.

CFLs contain mercury, an important issue in the disposal of these lamps. Several hazards result from broken lamps. The most serious are injuries or cuts from the phosphor-coated glass, and mercury vapour. If phosphor gets into the wound, it prevents blood clotting and interferes with healing. Inhalation of mercury vapour is extremely dangerous and a severe risk to health, causing respiratory tract damage, brain damage, kidney damage, central nervous system damage, and many other serious medical conditions even for small doses. No matter how small the amount of mercury, it is harmful to air, and water quality if not properly handled (www.consumerpower.org/new/index.php, 2003). This calls for policy measures to put systems in place for the proper disposal of CFL lamps to avoid the risk of creating areas of mercury contamination in buildings, landfills and rivers. Elsewhere, waste handlers are ordered by the Environmental Protection Agency to treat fluorescent lamps as hazardous and dispose them under special conditions. In the United States, for example, used or broken CFLs are sent to recycling centres that break the lamps and safely recover the mercury. Information and policies on proper disposal is crucial for proper environmental stewardship and for improving the quality of life.

The problem of disposal calls for effective Government action. Legislation on waste management and hazardous substance control is fragmented, administered by several different government departments, and there is no specific legislation for dealing with hazardous waste such as fluorescent lamps. The Environment Conservation Act of 1989 governs the disposal of waste and its management, and the waste management provision of the Act falls under the Department of Water Affairs and Forestry. The Hazardous Substances Act of 1973 controls hazardous substances, and the Act is not clear whether mercury is specifically listed as a Group 1 substance. There is ambiguity as to whether the fluorescent tubes should be disposed of at landfill sites due to their high mercury content. There is no legal requirement to force the manufacturer or consumers of CFLs to treat or dispose of them in an environmentally friendly manner.

\section{Conclusion}

The CFL offers considerable increase in energy efficiency compared to the standard incandescent lamps, which cannot be contested. The use of efficient lighting reduces power demand on the national electricity network, particularly at peak times, and provides significant economic and environmental benefits.

Consumers need more information in order to make rational choices especially on the quality of the product. While the 'green leaf' logo or any other form of distinguishable brand serves as a basis for development of purchase specifications, aggressive marketing will help consumers distinguish between the high quality and inferior products, thus breaking the vicious circle of low volume and high price. Just as it is important to promote the CFLs, South Africa does not have focused legislation for dealing with hazardous waste. Appropriate mechanisms have to be put into place for the safe disposal of CFL lamps in an environmentally friendly manner, so as to optimise their benefits in the residential sector.

\section{References}

Beckstead, J and Boyce P 1992. Structural Equation Modelling in Lighting Research: An Application to Residential Acceptance of New Fluorescent Lighting. Lighting Research and Technology, Vol. 24, No. 4.

Boardman, B and Darby S 2000. Effective Advice Energy Efficiency and the Disadvantaged. Executive Summary. ECI RESEARCH REPORT 24 http://www.eci.ox.ac.uk/.

Clark, A 1997a. Energy-Efficient Lighting in an Imperfect Market: Preliminary Thoughts for South Africa. Energy and Development Research Centre Report. University of Cape Town.

Clark, A 1997b. Economic Analysis of Eskom's Energy Efficient Lighting Programme for Low-income Households. Energy and Development Research Centre Report. University of Cape Town. 
Clark, A 1997c. Compact Fluorescent Lamps in an International Context. Energy and Development Research Centre Report. University of Cape Town.

Clark, A and Barberton, C 1999. Barriers Inhibiting Investment in DSM in South Africa. Energy and Development Research Centre Report. University of Cape Town.

Clarke, A 2001. BONESA: Review. Unpublished work undertaken for Eskom.

Commission of Inquiry into Thor Chemicals. Report of the First Phase 1997.

Davis, M 1998. Rural Household Energy Consumption: The Effects of Access to Electricity - Evidence from South Africa. Energy Policy, Vol. (26) No. 3.

ElektroWISE 2000 Eskom RSDM Report.

ELI South Africa Strategy Document. Prepared by: Bonesa (Pty) Ltd, for UFISA and Eskom. 27 October 2000.

ELI South Africa Strategy Document. Prepared by: Bonesa (Pty) Ltd for UFISA and Eskom. 30 November 2000.

Eskom 1998 Annual Report.

Eskom 1999 Annual Report.

Eskom 1999 Environmental Report.

Kofod, C 1996. Large CFL Potential in European Homes. IAEEL Newsletter 3/96 http://195.178.164.205/ IAEEL/ aeel/newsl/1996/tre1996/LiMa_b_3_96.html.

Palmer, J and Boardman B 1998 Domestic Efficient Lighting. Delight.

Simonds, G and Clark, A 1998. Energy Strategies for the Urban Poor. Energy and Development Research Centre Report. University of Cape Town.

Veich, J 1994. The Psychology of Choice. IAEEL Newsletter.

Received 31 July 2003; revised 6 August 2004 